\title{
Teaching Minimalist Music at the Fundamental Level: Performance Preparation and Stage Fright
}

\author{
Ang-Cheng Kris Ho and Victor J. Rodriguez
}

\begin{abstract}
Minimalist music offers string players, particularly young string players, a way to broaden their performance repertoire and enhance knowledge of their playing skills. Minimalist music also offers young string players an array of different learning materials that could transform their performance experience and utilize technological equipment into practice. Minimalist music was developed in the 1960s and, although most of the skills necessary to play it are not new or invented, its technical requirement and stage setting differ radically from the existing musical tradition. During the teaching and learning process, music educators should consider how stage fright could affect young string player's performance, how to develop aural skills in the musical training and how stage setting structures before a live performance. This research will investigate these demands of minimalist music on young string players.
\end{abstract}

Index Terms-Minimalism, string playing, performance preparation, stage fright, aural training.

\section{INTRODUCTION}

The unique relationship between music educator, performer, and composer has produced new challenges to the performance of contemporary music. This fact has led string players and students today to broaden their performance repertoire, especially into minimalist music. Although most music written for violin is still based on conventional playing techniques, minimalist music has extended and combined them with new innovations such as the click track, pickup, loop and pre-recorded recordings.

This research will examine the characteristics of learning and playing minimalist music for the basis of the string performance. It introduces suggestions for the teaching minimalist music at the beginner's level of string playing including performance preparation and stage fright. It also prescribes related subjects to learn and perform minimalist music. Instead of simply examining existing treatises or books, the learning strategy is to explore the brief historical background of minimalism and the application of conventional learning techniques to minimalist music followed by a review of selected composition by Terry Riley (b. 1935).

In this research, conventional playing techniques refer to

Manuscript received March 4, 2018; revised October 29, 2018. This work is supported by Beijing Normal University-Hong Kong Baptist University, United International College research grant.

Ang-Cheng Kris Ho is with the Beijing Normal University-Hong Kong Baptist University, United International College, Zhuhai, Guangdong, China (e-mail: krisho@uic.edu.hk).

Victor J. Rodriguez is with Sino-American College (SUC) at Beijing Institute of Technology, Zhuhai, Guangdong, China (e-mail: victor.rodriguez@suc.bitzh.edu.cn). skills which are not new nor invented but that can help violin players to understand and learn violin music from a different perspective. The fundamental level refers to a string player, who is able to read the music and can utilize basic right-hand and left-hand skills such as détaché (any notes not linked by a slur), legato (connected without any intervening silence of articulation), shifting (the sliding of the left hand to a new position on the fingerboard) and string-crossing. These techniques are fundamental playing techniques commonly applied by minimalist composers.

Through minimalist music, music educators and students will have more choices to explore different techniques in the learning process. Music educators and performance students might have listened to minimalist music through existing recordings or videos, but may have not considered it as a main learning tool or included a minimalist work as part of the performance repertoire. Based on performance preparation, stage setting, stage fright, and aural training exemplified by selected examples, it would enable teachers to train string players at the fundamental level with different concepts in their learning process. Riley's In $C$ (1964) is offered as an example of how to utilize minimalist music as learning material and how it can become a choice for the string performance repertoire.

\section{Minimalism IN THE 1960S AND 1970s}

Minimalism, as a visual art movement, began in the 1960s and early 1970s. Minimalism has become a term now applied to many fields such as visual art, sculpture, painting and architecture in the twentieth century. [1] In music, minimalist music is a musical art that represents a reaction in contrast to other music styles such as serialism and abstract expressionism. Minimalist music typically features repetition, consonant harmony, steady pulse, reiterative phrases and use of technology. These main features were established by New York-based American composers in the 1960s in New York. La Monte Young (b. 1935) and Terry Riley (b. 1935) are regarded as pioneer composers followed by Steve Reich (b. 1936), Philip Glass (b. 1937) and later John Adams (b. 1947). Young was noted for its application of Indian instrumental sound into his composition. Riley was known for the duration of the music and loop. Reich is known for his African rhythmic patterns, tape recording and religious influence; Glass is recognized for his use of ostinato, arpeggio and repeating rhythms as well as jazz elements. [2] Adams is noted for his technical demand and exploring sound in compositions.

When should string players start learning contemporary music history such as minimalism? There is no exact set time, 
it could gradually introduce and balance with various materials at the early learning stage, particular to young string players. Learning and teaching minimalist music should combine two forms of knowledge: its historical background and playing techniques. The extension of playing techniques yields a musical interpretation, which has a direct connection with the development of related history. Modern and contemporary music is not as familiar as the Baroque (1600-1750) and Classical music (1750-1820) to young string players and music amateurs. They could learn the history of modern music (since 1945) in order to improve their understanding of musical styles to be applied into the performance. Minimalist music, as part of the contemporary music style, not only requires mastering playing techniques but also involves the crafts of stage arrangement and mental and physical training which is an extension of the requirement in the teaching and learning process. Music educators could also use another way to introduce history and related issues into teaching strategy. Instead of learning history through the traditional timeline, students could learn the music backwards in time; this can be useful. For fundamental level learners, they can start what it looks like to live now. They can build backwards and extend that way in music learning and playing.

\section{Teaching Strategy of Minimalist Music at the FUNDAMENTAL LEVEL}

The learning strategy is normally affected by the student's personality, capability, musicality, playing technique development and aspirations in performing music on the stage. [3] Common questions could be considered in the teaching and learning plan; for instance: 1) what is a good piece to start learning minimalist music?; 2) when should the teacher begin using minimalist music as one of the learning pieces? and, 3) can these pieces be performed in the concert? Besides learning repertoire and history, teaching and learning minimalist music at the fundamental level, string teachers should consider several elements and include them in the plan. The consideration should consist of performance preparation, stage setting, aural training and particularly stage-fright. [4]

Minimalist music normally requires different stage settings and the use of electronic equipment such as audio systems indicated by composers. Stage setting has appeared direct or indirect relationship in stage fright. It will affect the player's presentation and interpretation in the concert. The conventional stage setting is very simple: only a piano, one solo instrument with or without a stand placed next to the piano. For example, American modernist composer, Charles Ives (1874-1954) in his violin sonata no. 4 Children's Day at the Camp Meeting (1911-16), only requires a piano to be placed on the stage just like most traditional classical compositions. However, the contemporary music stage setting can be complicated, which frequently includes a computer, an audio system, and other related equipment, based on the composer's instructions. For instance, Steve Reich (b. 1936) in his Violin Phase (1967) indicates for violin and pre-recorded tape or four violins and his later composition, The Cave (1990-93) requires six screens, video projectors, and multi-channel synchronized video playback.

\section{A. Performance Preparation}

Performance preparation includes metal persistency and physical endurance. String players are analogous to athletes, requiring strengthening of mental determination and intensive demands on physical routines. String players should discover the possibilities of musical problems and explore ways to improve performance. Minimalist music is a type of music with mental and physical demands as provided by the performance repertoire plan.

Traditional musicians learn from other musicians or teachers [5] but they are not able to discuss music with composers because most of music we play today are Baroque, Classical, Romantic music or music written before 1900. The benefit of learning music written after 1945 music such as minimalist music is that musicians can speak to the composer directly, have a correspondent connection with a composer, play with the composer or read an interview-text written by a scholar. An Interview with Steve Reich written by Gabrielle Zukerman in 2002 is an example of it. [6] Another example of receiving direct advice from an existing composer and performer in learning minimalist music is made by Dr. Robert Davidson (b. 1965), Australian minimalist composer and bassist. Davidson has commented on learning Reich's Violin Phase (1967) and Riley's In C (1964). As string players, we are familiar with the use of repetition in practice. The progression and preparation of learning minimalist music in practice would be directly transformed in the performance. (R. Davidson, personal communication, January 31, 2018)

Practice takes an important role in the performance preparation. It is like running a marathon; processing the music which would be performed for any of circumstances. It is a type of performing art and is governed by the principle of interaction in the performance. String players should regard each practice as a real performance. "The indispensable fundamental focus of practice routine is to maintain in perfecting tone, intonation, and rhythmic accuracy."( $R$. Davidson, personal communication, January 31, 2018)

For all levels, especially for pre-intermediate and fundamental students, open string practice is a good exercise to start learning fundamental bowing techniques such as legato to understand different parts of the bow. They should pay attention during early preparation on bowing techniques, from the frog to the tip, all different parts of bow contacts, string crossing and double stop exercises. These techniques will be discussed followed by listening, musicality, interpretation, and fluency with different musical compositions.

String playing involves a variety of playing techniques mainly focused on physical endurance and mental persistency. Minimalist music often employs a lot of conventional playing techniques on the left-hand and right-hand. These techniques include repetitive motion, ballistic motion, and controlled and circular motion. It challenges coordination between fingerings and bowings. It is not an individual motion but is often combined to form a compound movement. Most elements of minimalist music reveal these compound motions, such as broken chords, melody transformation and looping. Playing techniques on 
strings is one of the most important training exercises to be considered and introduced to young players throughout the learning process and practice routine. As commented by British-Australian violinist, Peter Tanfield (b. 1961), string playing techniques, particularly violin playing, involves physical action to produce sound and mental thinking in bowing and fingering. (P. Tanfield, personal communication, February 19, 2018)

Besides intensive playing techniques exercises in performance preparation, aural training is part of key points that must be considered and applied into practice routine and training at the fundamental level. Aural training, part of performance preparation practice, which should be maintained in the regular learning process to establish artistic ability in music performance. Aural training contains various concepts: rhythm, melody, and harmony. In minimalist music, intonation involves of repetitive patterns, intervals varied by steady rhythmic changes. If you can sing in tune, you should be able to play in tune.

Performance preparation and teaching fundamental string players requires serious plan and rigorous thinking in teaching. Each player needs a different plan or training based on their improvement in playing skills and physique development. First, balancing between left-hand and right-hand is the key point in coordinating position and posture. Second, players might focus on a specific physical training plan that distracts them from a short to a long duration practice. Third, selecting specific musical phrases and patterns within the pieces as part of mental management is more important than memorizing the whole piece. ( $\mathrm{P}$. Tanfield, personal communication, February 19, 2018.)

Minimalist music is normally written in repetitive patterns, which is a good source to be adapted as a practice routine. It requires the string player to work on the endurance of various patterns all together throughout the whole piece. [7] Second, string players are like athletes or marathon runners who have to utilize and perceive different parts of the body muscles to find time to react and rest. Physic preparation should establish a solid foundation for posture, position and finger movements in the practice routine: how to balance the tension and pressure of muscles is important to the performer. Human beings normally cannot maintain the same posture for a long time, otherwise, physically they get tired.

\section{B. Stage Setting}

Stage setting, as part of performance practice preparation is important in minimalist music performance or playing with real-time electric instruments. Traditional trained string players do not or rarely have experience using pedal or playing with a loop on stage. Controlling the pedal or using headphone while playing or performing might be strange and get nervous. While talking about performance, stage fright is a kind of physical reaction, which commonly happens to young string players. However, it could happen anytime and to anyone, even experienced performers or musicians. String players could practice using a loop, click track, pedal or pre-recorded tracks in any circumstance before the live performance. They are all essential tools that can be used to practice and perform in concert. Particularly, using click track to maintain the tempo of the music requires playing with loops or pre-recorded tracks in the live performance. Violin Phase (1967) written by Steve Reich (b. 1936) and Le Marteau Double (2003) for ensemble and pre-recorded audio (midi-marimba/vibes and midi piano) composed by French composer Patrick Dorobisz (b. 1955) are an example of it.

\section{Stage Fright}

Stage fright is always an issue related to string performance, discussed by string educators and performers in the learning process. Different people face different symptom of anxiety, mental or physical in string playing. In the 1973 book Stage Fright: Its Causes and Cures and the 1991 video A New Approach on the Causes and Cures of Physical injuries in Violin and Viola Playing, Kató Havas (b. 1920) discusses and analyzes stage fright especially in relation to violin playing. [8], [9] Stage fright symptoms commonly, known as anxiety, appear such as obvious dry throat, sweaty hands and feet, tense muscles and stiff body movement. [10] Getting nervous also burns out calories very fast and elicits desire to use the toilet. The performer easily feels hungry, digest carbohydrates and metabolism process faster than off-stage condition. Stage fright can be avoided and can be reduced in any of circumstances. The general symptom of this terrifying anxiety is when the player starts sweating and the bow hand starts shaking. [11]

The medical treatment would be the first and fastest way to reduce the physical symptoms of anxiety. It is certainly not the best choice to solve the problem of stage fright. Anxiety includes two parts: physical anxiety and mental anxiety. The performer should receive a prescription from the general practitioner and get beta blockers from the pharmacy shop. However, most of players should appraise it carefully as a long-term career plan for health management. Taking a beta blocker tablet or using similar medication is certainly not suitable for a long-term use and not good for the health particularly for young string players. It is necessary to contemplate several questions. First, what potential mental and physical reaction or movement would trigger the stage fright before the performance. Second, how the player can overcome this battle. Third, what solution is preferred rather than taking the beta blocker tablet. Third, the physical training one could combine with daily exercise such as scales and etude. Finally, what mental preparation could be introduced in the training, for instance, concentration and imagination of the final performance.

\section{A Case Study: Riley's in C (1964)}

In $C$, written by Terry Riley (b. 1935) in 1964 consists of 53 phrases and each phrase may be repeated a various numbers of times in a sequence. Players have the freedom to play a numbers of times and change to next phrase any time. Riley suggests the music can be presented in any kind of instruments. It can be performed with about thirty-five players or with smaller or larger groups. [12] In $C$ is a piece that can train and help young musicians to receive experience transition from solo performance to small ensemble. It is a piece, has not set duration, but Riley indicates the performance normally last at least forty-five minutes. It could be performed with numbers of performers, which will deliver a better sense of minimalist feeling to the audience. 
They should be trained in precise counting beats and intonation and gained ensemble skills. The piece can also teach young string players at the fundamental level how to confront the anxiety on the stage; the player should not think he or she would or might make a mistake in the actual performance. In $C$ is a piece to mainly stay on first finger position and bowing techniques are only legato and slur. (See Fig. 1) Riley gives the performer the freedom to play different patterns in different numbers. For young players, they could focus on intonation, rhythmic pattern and tone production as well as musical expression. Young string players should keep in mind that no performance is perfect and nobody will remember the few mistakes made in the performance. The player should help him or herself to establish mental training and be confident on self-performance. String educators could encourage young players to think positive, concentrate on the music score, and focus on what would be done in the performance. The most important thing is to maintain a regular practice and always confront all circumstances on the stage with patience and self-confidence.

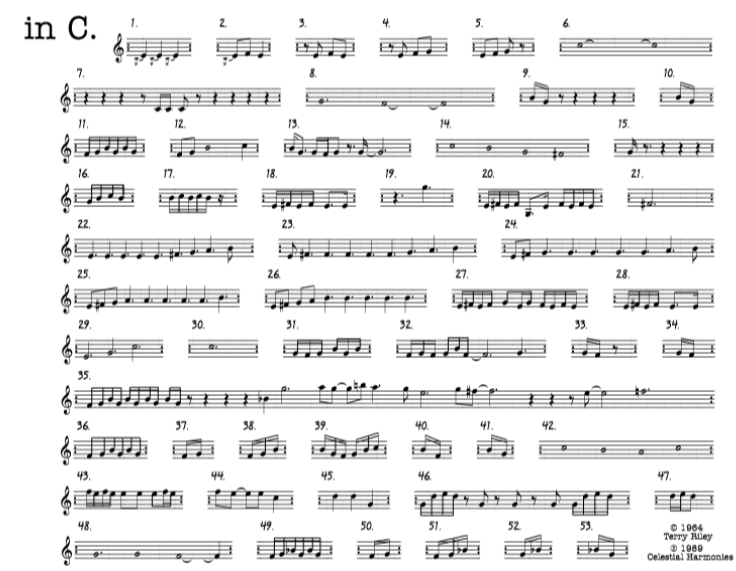

Fig. 1. Terry Riley's In C. [13].

As discussed in the section on performance practice, aural training constitutes a part of the fundamentals in performance practices. The listening skill would affect directly musical expression, tone production and rhythmic counting in the live performance as a result. [14] Playing minimalist music has benefits to maintain musical expression in mental determination and physical motions. Bowing techniques such as legato and string crossing can explain the relationship between left-hand and right-hand techniques. Minimalist music can also train the fundamentals of rhythmic counting and phrase shaping, especially since minimalist music normally processes the same patterns or phrases for a number of times. It is a good way to train your brain and coordinate body movements with muscles.

In learning to play minimalist music such as $\operatorname{In} C$, a string player should incorporate aural training into daily practice or routine as well as in a regular lesson's plan, particularly for beginners and intermediate students. Aural training normally seeks to identify pitch, interval, melody, chord, rhythm, and related musical elements of tonal music, based on Baroque, Classical and Romantic music. These skills are very useful and important throughout the conventional musical training regime. In $C$ starts from a quarter note $\mathrm{E}$ with acciaccatura note $\mathrm{C}$; based on this idea, the music gradually develops varying by different rhythms and intervals. (See Fig. 1) For a string player, it is a good practice for beginners who start learning string crossing, double stops and bow control. The interval is based on major and minor second and third intervals. The string player could practice $\mathrm{C}$ major, $\mathrm{A}$ minor and $\mathrm{C}$ minor scales to improve intonation. In the meantime, the player should practice different bow contact such as between upper half of the bow and the middle of the bow. The tone connection should be coordinated and the sound should be smooth and legato. One of minimalist music characteristics is its steady tempo and beats. Minimalist music normally lasts at least twenty minutes. It is not easy to maintain the tempo and beats exactly the same from the beginning to the end. Therefore, the player should practice with the metronome. In $C$ is a piece that can help the beginner-intermediate and/or young player to establish a good sense of musical expression, achieve accuracy of intonation and ensemble skills. These abilities can be extended and used in different compositions. In $C$ is a piece can encourage young string players to establishing aural skills, playing techniques and minimalist knowledge into their practice routine and later in the performance.

\section{FUTURE PLAN}

Modern and contemporary musical performance requires the incorporation of specific aural skills training into practice routine and performance practice. It also requires various stage and technology settings that should be included in the practice routine as well as the performance preparation. Minimalist music takes an important role in contemporary music history and performance. Using minimalist music as part of the learning materials for string teaching is not a new developed method but one rarely chosen by string educators or musicians. It can offer students an opportunity to learn different string playing techniques as well as enlarging their musical expression. It can also assist students to apply music technology (such as delay, loop or click track) into their daily exercise and enhance their performance experience. It will help young string players to establish an accurate sense of tempo control and counting beats as well as precise intonation. Minimalist music can use as a guide for young string players to broaden their playing skills and to establish a better manner of mental training to reduce stage fright in the performance. This study seeks to provide young string players with important ways to explore various learning methods, practice routine and prepare for the final performance. This research will be broadened and extended deeper in the future.

\section{CONCLUSION}

The connection between music educator, string players, and composer has revealed a new challenge to contemporary music performance and education. The contemporary repertoire especially in minimalist music will allow string musicians and young string players to broaden their performance repertoire, strengthen conventional playing 
techniques and acquaint them with new technology.

This research has used selected minimalist compositions in integrating discussion and commentary from an existing music educator, composers and personal teaching and learning experience. A case study of In $C$ has demonstrated learning methods for performance preparation, stage setting, management of stage fright and aural training. These methods should enable teachers to train young string players throughout their learning process. It will also assist the music educator and students to organize a better study plan before proceeding to the final stage of the performance.

\section{ACKNOWLEDGMENT}

Firstly, this research is supported by the research grant provided by Beijing Normal University-Hong Kong Baptist University United International College. Secondly, authors would like to express their gratitude to Dr. Robert Davidson and Mr. Peter Tanfield, who have given valuable comments, suggested musical connections and shared their personal thoughts for this research.

\section{REFERENCES}

[1] H. Obendorf, "In search of "Minimalism" - Roving in art, music and elsewhere," Minimalism: Designing Simplicity, London: Springer, 2009 , p. 23.

[2] H. Obendorf, "In search of "Minimalism" - Roving in art, music and elsewhere," Minimalism: Designing Simplicity, London: Springer, 2009, pp. 41-51.

[3] M. Kaschub, and J. Smith, "'Changing space where learning occurs' in music teacher education in transition," Promising Practice in 21st Century Music Teacher Education, New York: Oxford University Press, 2014, pp. 6-7.

[4] C. Tomlinson and K. Havas. Beyond Stage Fright. [Online]. Available: http://www.beyondstagefright.com/kato-havas/

[5] M. Kaschub and J. Smith, “'Changing space where learning occurs' in music teacher education in transition," Promising Practice in 21st Century Music Teacher Education, New York: Oxford University Press, 2014, p. 11.
[6] G. Zukerman, An Interview with Steve Reich, St. Paul, MN USA American Mavericks, American Public Media, July, 2002.

[7] K. Gann, "A forest from the seeds of minimalism: An essay on postminimal and totalist music," Minimalism Festival of the Berliner Gesellschaft fur neue Musik, 1998.

[8] K. Havas, Stage Fright: Its Causes and Cures with Special Reference to Violin Playing, 6th ed. London: Bosworth \& Co. Ltd, 1973.

[9] K. Havas, A New Approach on the Causes and Cures of Physical Injuries in Violin and Viola Playing, Cumbria, England: Bill Watkinson Associates, 1991.

[10] C. Duffner, "Intervista con kató havas," A Tutto Arco. European String Teachers Association, May 2008, pp. 14-21.

[11] K. Havas, A New Approach to Violin Playing, Yehudi Menuhin, Foreword, San Diego, CA: Bosworth Publishing Company, 2003.

[12] T. Riley, Performing Direction, New York: Associated Music Publishers Inc, 1964

[13] T. Riley, In C. Chester, New York: Associated Music Publishers Inc, 1964.

[14] M. Kaschub and J. Smith, "'Listening to music' in music teacher education in transition," Promising Practices in 21st Century Music Teacher Education, New York: Oxford University Press, 2014, pp. 6-7.

Ang-Cheng Kris Ho completed the $\mathrm{PhD}$ in violin performance from the University of Tasmania, Australia. She has extensive performance experience performing with international well-known musicians. Kris is specialized in violin performance and string pedagogue and her research is to focus on areas of contemporary violin music. Her present professional occupation is an associate professor of music, a music minor program designer and Division of Culture and Creativity, Beijing Normal University-Hong Kong Baptist University United International College Zhuhai, China.

Victor Jose Rodriguez received a doctor of philosophy in history from UCLA in Los Angeles, California, USA. His research is mainly focused on American history especially on issues of education, music education, media and literacy. His latest book Creating the Practical Man of Modernity: The Reception of John Dewey's Pedagogy in Mexico, was published by Routledge in 2016. Currently, Dr. Rodriguez serves as the acting director of the General Education Department and as an associate professor of history at the Sino-American College (SUC) at Beijing Institute of Technology, Zhuhai, Guangdong, China. 